\title{
SIMULASI BANTUAN HIDUP DASAR (BHD) DI SMK KESEHATAN SENTRA MEDIKA MEDAN JOHOR
}

\author{
Henny Syapitri ${ }^{1}$, Johansen Hutajulu ${ }^{2}$, Rumondang Gultom ${ }^{3}$, Rosetty Sipayung ${ }^{4}$ \\ ${ }^{1,2,3,4)}$ Program Studi Ners, Fakultas Farmasi dan Ilmu Kesehatan Universitas Sari Mutiara Indonesia \\ email: heny_syahfitri86@yahoo.com
}

\begin{abstract}
Abstrak
Kondisi gawat darurat dapat terjadi akibat dari trauma atau non trauma yang mengakibatkan henti nafas, henti jantung, kerusakan organ serta perdarahan. Kegawatdaruratan bisa terjadi pada siapa saja dan dimana saja, biasanya berlangsung secara cepat dan tiba-tiba sehingga tak seorangpun yang dapat memprediksikan. Dengan pemahaman yang utuh tentang konsep dasar gawat darurat, maka angka kematian dan kecacatan dapat ditekan serendah mungkin. Salah satu bentuk pertolongan medik yang perlu dimiliki adalah Bantuan Hidup Dasar. SMK Kesehatan Sentra Medika Johor berdasarkan peta geografis bahwa sekolah tersebut berada didaerah jalan protokol yang memungkinkan banyak terjadinya kasus kecelaakaan. Kegiatan pengabdian Masyarakat ini bertujuan untuk meningkatkan kemampuan siswa SMK Kesehatan Sentra Medika Medan Johor untuk melakukan simulasi pelaksanaan bantuan hidup dasar. Kegiatan ini dilaksanakan di SMK Kesehatan Sentra Medika Medan Johor. Peserta yang mengikuti kegiatan ini sebanyak 45 orang dan mereka sangat antusias mengikuti kegiatan simulasi pelaksanaan bantuan hidup dasar ini. Hasil kegiatan pengabdian masyarakat menunjukkan bahwa pengetahuan siswa/siswi sebelum dilakukan simulasi BHD mayoritas pengetahuan nya adalah kurang, yaitu sebesar 55,5\%, pengetahuan siswa/siswi sesudah dilakukan simulasi BHD mayoritas pengetahuan nya adalah Baik, yaitu sebesar 77,8\%, keterampilan siswa/siswi sebelum dilakukan simulasi BHD mayoritas keterampilan nya adalah kurang, yaitu sebesar $71,1 \%$. Diharapkan pihak pengelola SMK Kesehatan Sentra Medika Johor melakukan perencanaan pelatihan BHD secara rutin, menyediakan alat dan bahan seperti pantom RJP Bayi, Anak dan Dewasa untuk digunakan siswa praktik tindakan BHD agar dapat meningkatkan pengetahuan siswa dalam memberikan BHD pada pasien/korban kondisi darurat.
\end{abstract}

Kata Kunci : Simulasi, Bantuan Hidup Dasar (BHD)

\begin{abstract}
Emergency conditions can occur due to trauma or non-trauma that occur stop breathing, cardiac arrest, organ damage and bleeding. Emergency can happen to anyone and anywhere, it can happen suddenly and suddenly so there is nothing more that can be predicted. By fully understanding the basic concepts of the emergency department, the mortality and disability rates can be reduced as low as possible. One form of medical help needed is Basic Life Assistance. Health Vocational School Sentra Medika Johor based on the existing geographical map in the area of the protocol road that allows many cases of accidents. This community service activity aims to improve the ability of SMK Johor Sentra Health Center students to implement emergency assistance. This activity was carried out at the Health Vocational School Sentra Medika Medan Johor. 45 people participated in this activity and they were very enthusiastic about the activity. The results of community service activities show that the knowledge of students prior to conducting BHD simulations lacks knowledge, which is $55.5 \%$, the knowledge of students / students carried out with BHD simulations understanding their knowledge is Good, that is equal to $77.8 \%$, the skills of students before being conducted BHD simulation Needs less skill, which is equal to $71.1 \%$. It is expected that the manager of the Health Vocational School of Medical Center in Johor conducts routine BHD training planning, provides tools and materials such as RJP infant, Child and Adult pantom to be used by students to practice BHD actions in order to increase students' knowledge in providing BHD to patients / victims of emergencies.
\end{abstract}

Keywords : Simulation, Basic Life Support (BHD) 


\section{PENDAHULUAN}

Bantuan Hidup Dasar (Basic Life Support) merupakan sekumpulan intervensi yang bertujuan untuk mengembalikan dan mengembangkan dan mempertahankan fungsi vital organ pada korban henti jantung dan henti nafas. Intervensi ini terdiri dari pemberian kompresi dada dan bantuan nafas. Kondisi gawat darurat dapat terjadi akibat dari trauma atau non trauma yang mengakibatkan henti nafas, henti jantung, kerusakan organ dan atau perdarahan. Kegawatdaruratan bisa terjadi pada siapa saja dan di mana saja, biasanya berlangsung secara cepat dan tiba-tiba sehingga tak seorangpun yang dapat memprediksikan (AHA, 2010).

Salah satu hal yang sangat penting untuk dipahami oleh semua profesi kesehatan termasuk orang awam yaitu konsep dasar gawat darurat. Ada tiga hal yang paling kritis dalam konsep dasar gawat darurat, yang pertama adalah kecepatan waktu kali pertama korban ditemukan, kedua yaitu ketepatan dan akurasi pertolongan pertama diberikan, dan yang ketiga adalah pertolongan oleh petugas kesehatan yang kompeten. Hampir $90 \%$ korban meninggal ataupun cacat disebabkan oleh korban terlalu lama dibiarkan atau waktu ditemukan telah melewati the golden time dan ketidaktepatan serta akurasi pertolongan pertama saat kali pertama korban ditemukan yang dibuktikan oleh statistik (Team INTC,2014).

Oleh sebab itu, pelayanan kedaruratan medik yang tepat dan segera sangat dibutuhkan agar kondisi kegawatdaruratan dapat diatasi. Dengan pemahaman yang utuh tentang konsep dasar gawat darurat, maka angka kematian dan kecacatan dapat ditekan serendah mungkin. Salah satu bentuk pertolongan medik yang perlu dimiliki adalah Basic Life Support (Putri, 2019).

Dari hasil penelitian Chandrasekaran dkk pada tahun 2010 di India menunjukkkan bahwa $31 \%$ kalangan medis, mahasiswa keperawatan, mahasiswa kedokteran gigi dan mahasiswa kedokteran tidak mengetahui singkatan BLS yang merupakan Basic life support, $51 \%$ gagal melakukan usaha penyelamatan sebagai langkah awal dalam bantuan hidup dasar, dan $74 \%$ tidak mengetahui lokasi yang tepat untuk kompresi dada pada tindakan bantuan hidup dasar (Rudski, L. G, 2010).

Tujuan bantuan hidup dasar ialah untuk oksigenasi darurat secara efektif pada organ vital seperti otak dan jantung melalui ventilasi buatan dan sirkulasi buatan sampai paru dan jantung dapat menyediakan oksigen dengan kekuatan sendiri secara normal (Yatma, D. P. A, 2015).

Pelaksanaan kegiatan simulasi pada siswa/siswi SMK Kesehatan Sentra Medika Johor berdasarkan peta geografis bahwa sekolah tersebut berada didaerah jalan protokol yang memungkinkan banyak terjadinya kasus kecelaakaan.

Studi yang telah dilakukan di 182 negara, salah satunya yaitu Negara Indonesia yang berada dalam urutan kelima dengan korban meninggal terbanyak yang diakibat kan oleh kecelakaan lalu lintas. Korps lalu lintas Mabes Polri mencatat pada tahun 2013, terjadi 101.037 kecelakaan lalu lintas. Hal ini berarti, terjadi 12 kasus kecelakaan lalu lintas setiap jamnya (Buamona, dkk. 2017).

\section{METODE}

Kegiatan pengabdian Masyarakat ini dialkukan di SMK Kesehatan Sentra Medik Johor. Kegiatan ini dilaksanakan pada tanggal 28 November 2019 Luaran yang diharapkan dari kegiatan ini yaitu siswa/siswi dapat memanfaatkan keterampilan simulasi pelaksanaan bantuan hidup dasar untuk menangani dan melakukan pertolongan pada korban dengan masalah bantuan hidup dasar. Peserta yang mengikuti kegiatan ini berjumlah 45 orang.

Kegiatan ini diawali dengan pemberian materi tentang Bantuan Hidup Dasar dan Demonstrasi Bantuan Hidup Dasar dalam aktivitas Sehari-hari Pada keluarga atau masyarakat yang membutuhkan pertolongan. Metode yang disampaikan menggunakan ceramah dan diskusi interaktif serta demonstrasi. Metode demonstrasi dilakukan setelah penyampain materi. Pada tahap ini siswa/siswi akan diuji coba mendemonstrasikan kembali kegiatan simulasi BHD dan nantinya dapat dipraktikkan pada masyarakat yang membutuhkan bantuan atau pertolongan dalam keadaan darurat.

\section{HASIL DAN PEMBAHASAN}

Hasil pelaksanaan Kegiatan Simulasi BHD di SMK Kesehatan Sentra Medika Johor dikemukakan sebagai berikut: 
Tabel 1

Pengetahuan Siswa/Siswi SMK Kesehatan Sentra Medika

\begin{tabular}{lcc}
\hline Pengetahuan & N & Persentase \\
\hline Sebelum Simulasi: & & \\
\hline Baik & 8 & 17,8 \\
Cukup & 12 & 26,7 \\
Kurang & 25 & 55,5 \\
\hline Setelah Simulasi : & & \\
\hline Baik & 35 & 77,8 \\
Cukup & 7 & 15,6 \\
Kurang & 3 & 6,6 \\
\hline
\end{tabular}

Tabel 2

Keterampilan Siswa/Siswi SMK Kesehatan Sentra Medika

\begin{tabular}{lcc}
\hline Keterampilan & N & Persentase \\
\hline Sebelum Simulasi : & & \\
\hline Baik & 3 & 6,7 \\
Cukup & 10 & 22,2 \\
Kurang & 32 & 71,1 \\
\hline Sesudah Simulasi : & & \\
\hline Baik & 27 & 60,0 \\
Cukup & 11 & 24,4 \\
Kurang & 7 & 15,6 \\
\hline
\end{tabular}

Berdasarkan tabel 1 dapat dilihat bahwa pengetahuan siswa/siswi sebelum dilakukan simulasi BHD mayoritas adalah kurang, yaitu sebesar 55,5\%, namun setelah dilakukan simulasi BHD pengetahuan siswa/siswi mayotias baik, yaitu sebesar $77,8 \%$.

Berdasarkan tabel 2 dapat dilihat bahwa keterampilan siswa/siswi sebelum dilakukan simulasi BHD mayoritas adalah kurang, yaitu sebesar 71,1\%, namun setelah dilakukan simulasi BHD keterampilan siswa/siswi mayortias baik, yaitu sebesar $60 \%$.

Metode simulasi Bantuan Hidup dasar (BHD) yang diterapkan pada kegiatan pengabdian ini sangat berperan penting, karena dapat meningkatkan pemahaman dan keterampilan siswa/siswi di SMK Kesehatan Sentra Medika Johor.

Metode simulasi yang digunakan merupakan metode yang sangat efektif diksarenakan mempermudah responden untuk menerapkan secara langsung (Sudjana, 2010).

Peningkatan pengetahuan dan keterampilan sesungguhnya tidak lepas dari dari pemberian pelatihan, sehingga tingkat pengetahuan dan keterampilan menunjukkan adanya perubahan setelah diberikan simulasi.

Hal tersebut juga didukung oleh penelitian Muniarti, dkk (2019) pada anak karang taruna dan setelah dilakukan simulasi, hasil kesimpulan menunjukan bahwa terdapat pengaruh yang signifikan antara simulasi BHD terhadap motivasi $(\mathrm{p}=0.000)$, skill $(\mathrm{p}=0.000)$, dan pengetahuan $(\mathrm{p}=0.000)$.

Oleh sebab itu diharapkan siswa/siswi dapat memanfaatkan pengetahuan yang sudah dimiliki untuk melaksanakan pemberian bantuan hidup dasar kepada korban yang mengalami henti napas dan henti jantung yang disebabkan karena korban mengalami serangan jantung (heart attack), tenggelam, tersengat arus listrik, keracunan, kecelakaan dan lain-lain. 


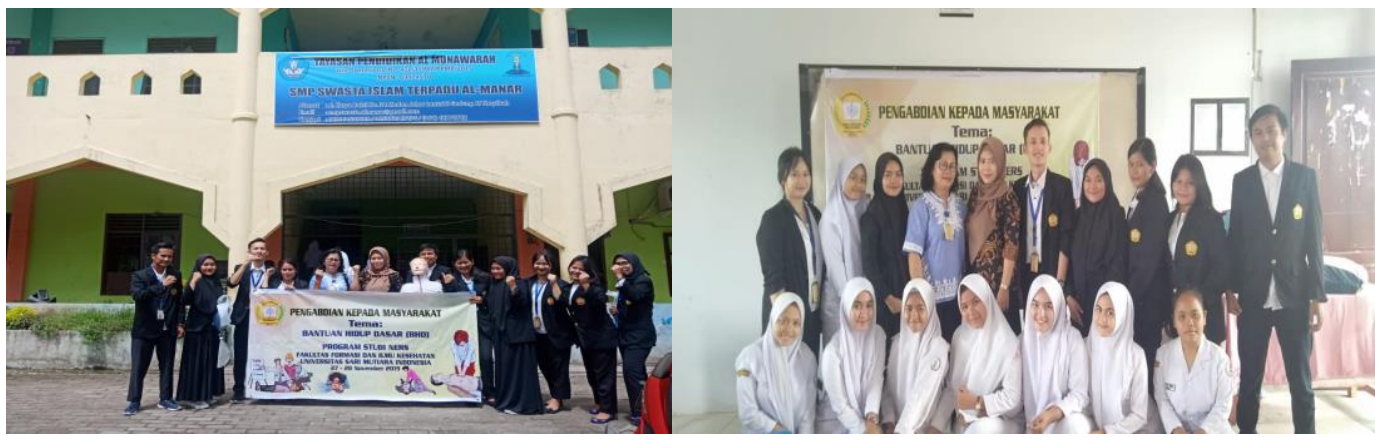

Gambar 1. Lokasi Kegiatan Simulasi

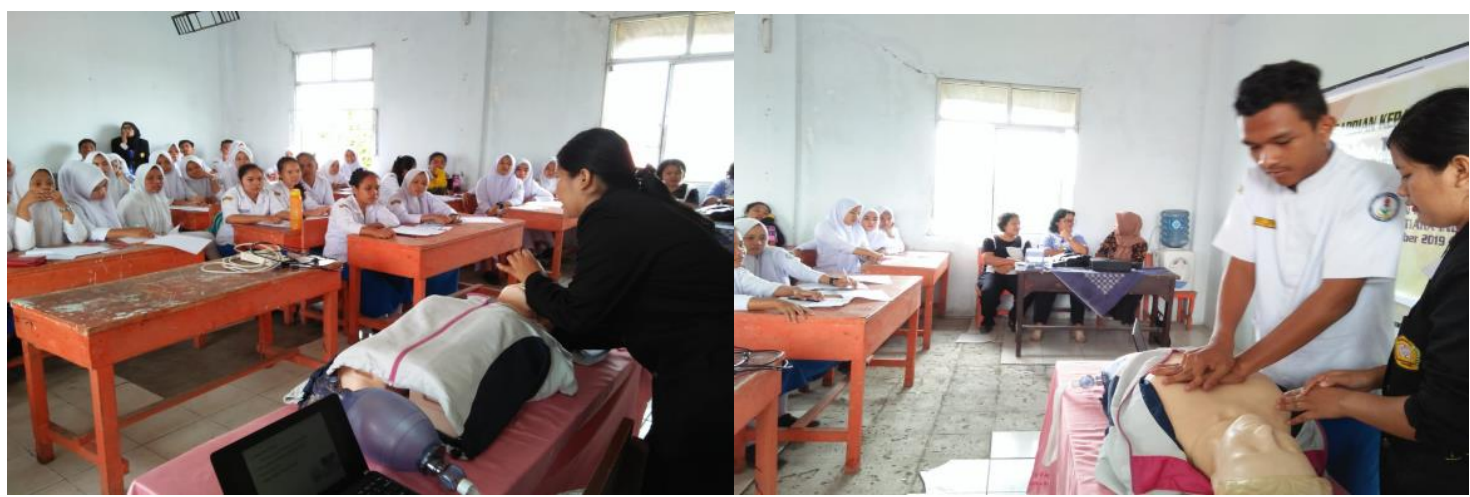

Gambar 2. Penyampaian Materi Simulasi

\section{SIMPULAN}

Respon siswa SMK Kesehatan Sentra Medika Johor sangat antusias, dimana dihadiri oleh seluruh siswa sebanyak 45 orang. Kegiatan simulasi BHD dapat terlaksana sesuai dengan tujuan dan rencana dan disambut dengan baik oleh siswa SMK Kesehatan Sentra Medika Johor dan mereka mengikuti kegiatan hingga selesai. Pengetahuan dan keterampilan siswa/siswi SMK Kesehatan Sentra Medika Johor meningkat setelah dilakukan simulasi bantuan hidup dasar. Kegiatan ini memberikan imformasi yang baru bagi peserta mengenai Bantuan Hidup Dasar

\section{SARAN}

Diharapkan pihak pengelola SMK Kesehatan Sentra Medika Johor melakukan perencanaan pelatihan BHD secara rutin, menyediakan alat dan bahan seperti pantom RJP Bayi, Anak dan Dewasa untuk digunakan siswa praktik tindakan BHD agar dapat meningkatkan pengetahuan siswa dalam memberikan BHD pada pasien/korban kondisi darurat.

\section{DAFTAR PUSTAKA}

Putri, dkk. (2019). Pelatihan Bantuan Hidup Dasar Dengan Media Phantom ResusitasiJantung Paru (Prejaru) Meningkatkan Pengetahuan Dan Keterampilan Bantuan Hidup Dasar Pada Orang Awam. Purwokerto : Jurnal Gawat Darurat.

AHA-American Heart Association. (2010). Part 4 : CPR Overview : 2010 American Heart Association Guidelines For Cardiopulmonary Resuscitation and Emergency Cardiovasculer Care, AHA Journals, 122 (4) : 676-684. http://circ.ahajournals.org/content/122/18_suppl_3.

Rudski, L. G., Lai, W. W., Afilalo, J., Hua, L., Handschumacher, M. D., Chandrasekaran, K., \& Schiller, N. B. (2010). Guidelines for the echocardiographic assessment of the right heart in adults: a report from the American Society of Echocardiography: endorsed by the European Association of Echocardiography, a registered branch of the European Society of Cardiology, and 
the Canadian Society of Echocardiography. Journal of the American Society of Echocardiography, 23(7), 685-713.

Team INTC. (2014). Basic Trauma Cardiac Life Support (BTCLS) In Disaster. Jakarta : Sagung Seto.

Buamona, S., Kumaat, L. T., \& Malara, R. T. (2017). Pengaruh Pendidikan Kesehatan Terhadap Tingkat Pengetahuan Bantuan Hidup Dasar (Bhd) Pada Kecelakaan Lalu Lintas Pada Siswa SMA Negeri 1 Sanana Kabupaten Kepulauan Sula Maluku Utara. JURNAL KEPERAWATAN, 5(1).

Yatma, D. P. A., \& Ruhyana, R. (2015). Efektivitas Metode Penyuluhan Audiovisual dan Praktik terhadap Tingkat Pengetahuan Bantuan Hidup Dasar pada Nelayan di Pantai Depok Yogyakarta. (Doctoral dissertation, STIKES'Aisyiyah Yogyakarta).

Sudjana, N. (2010). Penilaian proses belajar mengajar. Bandung: PT Remaja Rosdakarya. 